ADI WIDYA: Jurnal Pendidikan Dasar

FAKULTAS DHARMA ACARYA

INSTITUT HINDU DHARMA NEGERI DENPASAR
Volume. 4, Nomor 2 Oktober 2019

ISSN: 2685-8312 (online)

ISSN: 2527-5445 (cetak

http://ejournal.ihdn.ac.id/index.php/AW

\title{
PENINGKATAN MUTU PENDIDIKAN KELUARGA PADA ERA MILENIAL
}

\author{
Oleh: \\ I Kadek Ruminten; Gusti Nyoman Mastini \\ kadekruminten@gmail.com; gustinyomanmastini@gmail.com \\ Institut Hindu Dharma Negeri Denpasar
}

diterima 10 Agustus 2019, direvisi 16 September 2019, diterbitkan 1 Oktober 2019

\begin{abstract}
Human are creatures that struggle intensely with education. That is why humans are called the animal educandum and animal educandus at the same time as educated creatures and educational creatures. In other words, humans are creatures who are always involved in the process of education, both those done to others and to themselves. Weak character in the Indonesian people by fighting bad characters. The mental revolution in the nation consists of 18 characters that must be resisted, namely negative thinking, delaying work, not focusing, lacking in confidence, always pessimistic, lazy, ignorant, easy to give up, greedy, selfish, wasteful, dishonest, antichange, avoid responsibility, lack commitment, underestimate quality, feudal and hypocritical. Because this condition is background of the birth in character education consisting of 18 characters contained in the Indonesian nation's education, namely: religious, honest, tolerant, discipline, hard work, creative, independent, democratic, curiosity, national spirit, love for the country, respect for achievement, friendly / communicative, peace-loving, fond of reading, caring for the environment, social care, and responsibility (Jurnal kalangwan, Vol. 6, No. 1, Maret 2016:82). Character education has the same essence and meaning as moral education and noble moral education. The aim is to shape the child's personality so that they become better human beings, good citizens and citizens. Entering the millennial era, various changes occurred very rapidly. The main characteristic of the change that is happening in this millennial era is the rapid cultural change, so that the impact of educational institutions is doubtful, so that character education is not sufficiently taught within the school environment, but more importantly to be taught in the family environment because the family environment is the first and foremost child learning place. As well as character education can be made through a good community environment. Because of character development, it is influenced by the community environment where they live and play. The influence of society is very influential in association in the current millennial era. Because of new trends and new understandings adopted from westernization and globalization. So the way to grow character education through the family environment is the first and foremost place, supported by education in the school and community environment.
\end{abstract}

Keywords: Character Education, Family, Millennial Era. 


\section{Pendahuluan}

Karakter bangsa yang kuat mesti Agama, Sejarah, Kewarganegaraan, dan dibangun dalam diri peserta didik. Sebab lain sebagainya.

karakter menentukan lemah atau kuatnya Pendidikan di masyarakat tidak seorang individu. Didalam memberikan kalah pentingnya karena lingkungan pendidikan kepada peserta didik tidak masyarakat juga sangat berpengaruh hanya sebatas mentransfer ilmu saja, terhadap watak dan karakter seseorang. namun lebih utama yaitu bagaimana Lingkungan masyarakat luas sangat pendidikan itu dapat mengubah atau berpengaruh terhadap keberhasilan membentuk karakter dan watak seseorang penanaman nilai-nilai etika, estetika agar menjadi lebih baik, lebih sopan untuk pembentukan karakter. Oleh karena dalam tataran etika maupun estetika itu didalam penguatan moral peserta maupun dalam kehidupan sehari-hari. didik melalui pendidikan karakter tidak Pendidikan karakter merupakan upaya bisa terlepas dari lingkungan keluarga, yang melibatkan semua pihak baik sekolah, maupun lingkungan masyarakat. lingkungan keluarga, sekolah, maupun Krisis moral disebabkan oleh tidak masyarakat luas. Oleh karena itu, perlu efektifnya pendidikan nilai dalam arti penyambung kembali hubungan dan luas (di rumah, di sekolah, dan di jaringan pendidikan (educational masyarakat). Terpuruknya bangsa dan networks) yang mulai terputus tersebut. Negara Indonesia dewasa ini tidak hanya Pembentukan dan pendidikan karakter disebabkan oleh krisis ekonomi tersebut, tidak akan berhasil selama antar melainkan juga oleh krisis moral atau lingkungan pendidikan tidak ada akhlak mulia. Seperti dijelaskan oleh kesinambungan dan keharmonisan. Thomas Lickona dalam bukunya yang Dengan demikian, lingkungan keluarga berjudul educating for character, merupakan lingkungan yang pertama dan 2015:20-30 kekhawatiran terhadap anak utama dalam pembentukan pendidikan muda di era milenial saat ini tren anak karakter harus lebih diberdayakan. muda secara umum lebih cenderung

Sedangkan pendidikan karakter menunjukkan gambaran yang lebih melalui lingkungan sekolah, tidak kelam. Terdapat 9 indikasi yang perlu semata-mata pembelajaran pengetahuan mendapat perhatian agar berubah kearah semata, tetapi lebih dari itu yaitu yang lebih baik, kemunduran kesadaran penanaman moral, nilai-nilai etika, masyarakat yang perlu dibangkitkan agar estetika, budhi pekerti yang luhur dan perkembangan moral para pemuda dapat lain sebagainya. Pemberian penghargaan menjadi lebih baik. a). Kekerasan dan kepada peserta didik yang berprestasi tindakan anarki. b). Pencurian. c). dapat menumbuhkan semangat dari Tindakan curang. d). Pengabaian peserta didik dan memberikan sanksi terhadap aturan yang berlaku. e). kepada peserta didik yang melanggar Tawuran antar mahasiswa. f). aturan dapat mencegah terjadinya hal-hal Ketidaktoleran. g). Penggunaan bahasa yang tidak baik. Selanjutnya menerapkan yang tidak baik. h). Kematangan seksual pendidikan karakter dengan menerapkan yang terlalu dini dan penyimpangannya. kedalam setiap pelajaran yang ada i). Sikap perusakan diri. Dari disamping mata pelajaran khusus untuk permasalahan itu pendidikan karakter mendidik karakter, seperti; pelajaran merupakan solusi dari permasalahan tersebut maka sangat penting pendidikan 
ADI WIDYA: Jurnal Pendidikan Dasar

FAKULTAS DHARMA ACARYA

INSTITUT HINDU DHARMA NEGERI DENPASAR
Volume. 4, Nomor 2 Oktober 2019

ISSN: 2685-8312 (online)

ISSN: 2527-5445 (cetak

http://ejournal.ihdn.ac.id/index.php/AW karakter itu diajarkan kepada peserta didik seperti; Budi pekerti, Nilai, Norma, Moral dan lain sebagainya.

\section{Metode}

Metode penelitian yang digunakan dalam penelitian ini adalah metode kualitatif dengan pendekatan deskriftif kualitatif. Metode kepustakaan digunakan untuk mengkaji berbagai literatur yang terkait dengan metode pendidikan karakter ini. Nasution (2003:145) menyatakan bahwa setiap penelitian memerlukan bahan yang bersumber dari perpustakaan. Bahan ini meliputi buku, jurnal, majalah, pamflet, dan bahan dokumenter. Metode studi kepustakaan dipergunakan dalam penelitian ini untuk mencatat hal-hal atau pokok-pokok bahasan yang terdapat dalam sumber-sumber yang sesuai dengan topik penelitian.

\section{Pendidikan Karakter}

Pendidikan

merupakan

bimbingan yang diberikan kepada anak dalam masa pertumbuhan dan perkembangannya untuk mencapai tingkat kedewasaan dan bertujuan untuk menambah ilmu pengetahuan, membentuk karakter diri, sehingga menjadi pribadi yang lebih baik. Pendidikan menurut John Dewey (dalam Masnur Muslich, 2010:67) adalah proses pembentukan kecakapan fundamental secara intelektual dan emosional ke arah alam dan sesama manusia. Tujuan pendidikan dalam hal ini agar generasi muda sebagai penerus generasi tua dapat menghayati, memahami, mengamalkan nilai-nilai atau norma-norma tersebut dengan cara mewariskan segala pengalaman, pengetahuan, kemampuan dan keterampilan yang melatar belakangi nilai-nilai dan norma-norma hidup dan kehidupan.

$$
\text { Pengertian Pendidikan menurut }
$$

Ki Hajar Dewantara (dalam Hasbullah,2011:4) dijelaskan yaitu tuntunan di dalam hidup tumbuhnya anak-anak, adapun maksudnya, pendidikan yaitu menuntun segala kekuatan kodrat yang ada pada anakanak itu, agar mereka sebagai manusia dan sebagai anggota masyarakat dapatlah mencapai keselamatan dan kebahagiaan yang setinggi-tingginya. Menurut Undang Undang Sistem Pendidikan Nasional No. 20 tahun 2003 Pasal 1 ayat 1 dijelaskan bahwa "Pendidikan adalah usaha sadar dan terencana untuk mengwujudkan suasana belajar dan proses pembelajaran agar peserta didik secara aktif mengembangkan potensi dirinya untuk memiliki kekuatan spiritual keagamaan, pengendalian diri, kepribadian, kecerdasan, akhlak mulia, serta keterampilan yang diperlukan dirinya, masyarakat, bangsa, dan Negara" UU Republik Indonesia No. 20 Tahun 2003,2010:22 (dalam (Jurnal kalangwan, Vol. 6, No. 1, Maret 2016:84).

Usaha sadar dan terencana yang dimaksudkan bahwa orang dewasa/orang tua dari peserta didik telah merencanakan bahwa anaknya harus mendapatkan pendidikan karena setiap insan manusia berhak mendapatkan pendidikan agar setiap peserta didik mampu menggali potensi dirinya untuk memiliki sepiritual keagamaan, pengendalian diri, kepribadian, kecerdasan, akhlak mulia, serta keterampilan yang diperlukan dirinya nanti, serta masyarakat bangsa dan Negara sesuai dengan undangundang system pendidikan yang berlaku di Indonesia. 
ADI WIDYA: Jurnal Pendidikan Dasar FAKULTAS DHARMA ACARYA INSTITUT HINDU DHARMA NEGERI DENPASAR
Volume. 4, Nomor 2 Oktober 2019

ISSN: 2685-8312 (online)

ISSN: 2527-5445 (cetak

http://ejournal.ihdn.ac.id/index.php/AW
Demikian juga dijelaskan menurut Poerwadarminta, 1987:309 (dalam jurnal kalangwan Vol. 6,No. 1, Maret 2016:84) bahwa pendidikan adalah proses perubahan sikap dan tata laku seseorang atau sekelompok orang dalam usaha mendewasakan manusia melalui upaya pengajaran dan pelatihan. Dari beberapa pengertian pendidikan yang diungkapkan oleh para ahli pendidikan maka pada dasarnya sepakat bahwa yang dimaksud pendidikan ialah ilmu pengetahuan yang membicarakan masalah-masalah yang berhubungan dengan pendidikan. (Hasbullah,2011:8).

Kata karakter berasal dari bahasa yunani "to mark" atau menandai dan memfokuskan bagaimana mengaplikasikan nilai kebaikan dalam bentuk tindakan atau tingkah laku, sehingga orang yang tidak jujur, kejam, dan perilaku kurang baik lainnya dikatakan orang berkarakter kurang baik sebaliknya orang yang berprilaku sesuai dengan kaidah moral disebut dengan orang yang berkarakter mulia. Karakter mulia berarti individu yang memiliki pengetahuan tentang potensi dirinya yang ditandai dengan nilai-nilai seperti bertanggung jawab, disiplin, mandiri, kreatif, logis, jujur, bekerja keras dan nilai-nilai positif lainnya. Sedangkan karakteristik adalah realisasi perkembangan positif sebagai individu (intelektual, emosional, sosial, etika, dan perilaku).

Menurut Thomas Lickona, 1991 (dalam jurnal kalangwan Vol. 8, No. 1, Maret 2018:24), Pendidikan karakter adalah pendidikan budhi pekerti, yaitu yang melibatkan aspek pengetahuan (cognitive), perasaan (feeling), dan tindakan (action), tanpa ketiga aspek ini, maka pendidikan karakter tidak akan efektif. . Secara harfiah karakter artinya "Kualitas mental atau moral, kekuatan moral, nama atau reputasi" Hornby dan Pornwell, 1972:49 (dalam jurnal kalangwan Vol. 8, No. 1, Maret 2018:23). Pendidikan karakter adalah suatu usaha manusia secara sadar dan terencana untuk mendidik dan memberdayakan potensi peserta didik guna membangun karakter pribadinya sehingga dapat menjadi individu yang bermanfaat bagi diri sendiri dan lingkungannya. Dengan demikian dapat disimpulkan bahwa karakter merupakan nilai-nilai perilaku manusia yang berhubungan Tuhan Yang Maha Esa, diri sendiri, sesama manusia, lingkungan kebangsaan yang terwujud dalam pikiran, sikap, perasaan, perkataan, dan perbuatan berdasarkan norma agama, hukum, tata karma, budaya dan adat istiadat. Karakter itu berkaitan dengan kekuatan moral, berkonotasi "positif", bukan netral. Jadi, orang berkarakter adalah orang yang memiliki kualitas moral yang positif. Dengan demikian, pendidikan adalah membangun karakter, yang secara implisit mengandung arti membangun sifat atau pola perilaku yang didasari atau berkaitan dengan dimensi moral yang positif atau yang baik, bukan yang negatif atau yang buruk, (Masnur Muslich, 2010:71).

\section{Peranan Lingkungan Keluarga Dalam Pendidikan Karakter Pada Anak}

Lingkungan

keluarga merupakan lingkungan pendidikan yang pertama, karena dalam keluarga inilah anak pertama-tama mendapatkan didikan dan bimbingan. Lingkungan keluarga juga dikatakan lingkungan yang utama, karena sebagian besar dari kehidupan anak adalah didalam keluarga, sehingga pendidikan yang 
ADI WIDYA: Jurnal Pendidikan Dasar FAKULTAS DHARMA ACARYA INSTITUT HINDU DHARMA NEGERI DENPASAR
Volume. 4, Nomor 2 Oktober 2019

ISSN: 2685-8312 (online)

ISSN: 2527-5445 (cetak

http://ejournal.ihdn.ac.id/index.php/AW paling banyak diterima oleh anak adalah dalam keluarga.Tugas utama dari keluarga bagi pendidikan karakter anak ialah sebagai peletak dasar bagi pendidikan akhlak dan pandangan hidup keagamaan. Sifat dan tabiat anak sebagian besar diambil dari kedua orang tuanya dan dari anggota keluarga yang lain (Hasbullah, 2011:38).

Peran orang tua didalam menumbuhkan pendidikan karakter pada anak sangat begitu besar disamping anak tersebut mendapatkan pendidikan karakter dari sekolah ataupun dari masyarakat (PF, 2017). Bagi seorang anak, keluarga merupakan persekutuan hidup pada lingkungan keluarga tempat dimana ia menjadi diri pribadi atau diri sendiri. Keluarga juga merupakan wadah bagi anak dalam proses pembelajaran dalam rangka mengembangkan dan membentuk diri fungsi sosialnya. Keluarga juga sebagai tempat bagi anak untuk belajar dalam segala sikap,sopan santun,tata krama dan berbhakti pada tuhan yang maha esa sebagai perwujudan nilai yang tertinggi. Lingkungan keluarga memberikan pengalaman pertama yang merupakan faktor penting dalam perkembangan pribadi anak.

Pendidikan keluarga merupakan pendidikan yang pertama dan utama (Drs.H.Ahmadi,Dra.Nur

Uhbiyanti,2001:176). Kata "keluarga" dijelaskan menurut K.H. Dewantara adalah sebagai berikut: "Bagi bangsa kita perkataan keluarga tadi kita kenal sebagai rangkaian perkataan-perkataan kawula dan warga. Sebagai kita ketahui, maka kawula itu tidak lain artinya dari pada abdi yakni hamba sedangkan warga berarti anggota. Sebagai keluarga wajiblah seseorang disitu menyerahkan segala kepentingan-kepentingannya kepada keluarganya.

\section{Cara Menumbuhkan Pendidikan Karakter Di Era Milenial}

Pendidikan karakter sangat penting diajarkan pada anak pada saat usia dini,sehingga para generasi muda yang akan datang bisa memiliki moral dan karakter yang lebih baik. Perkembangan jaman turut mempengaruhi gaya anak dimasa sekarang ini,mereka menerima pengaruh budaya dari luar tanpa menyeleksi apakah budaya yang mereka tiru sesuai dengan kaidah norma yang ada di Indonesia atau tidak. Melunturnya moralitas dan karakter anak di jaman milenial ini tentu membawa dampak buruk bagi bangsa Indonesia dimasa yang akan datang. Melunturnya moralitas dan karakter anak ditandai dengan pergaulan anak diluar kendali orang tua seperti berpakaian yang serba mini, keluyuran pada saat malam hari, tawuran antar pelajar, melakukan hubungan badan diluar nikah dan bahkan menggunakan obat-obatan terlarang. Hal ini disebabkan oleh keadaan lingkungan keluarga tersebut seperti apa, jika keadaan lingkungan keluarga tersebut kacau tentu akan berdampak kepada anak sehingga tempat untuk anak mendapatkan pendidikan karakter tidak terwujud, akan tetapi jika keadaan lingkungan keluarga anak tersebut nyaman, aman, tentram, dan harmonis maka perkembangan anak tersebut tentu akan menjadi baik. Bangsa Indonesia kedepan ada ditangan para generasi muda saat ini.

Lantas bagaimana cara kita didalam menumbuhkan pendidikan karakter kepada anak terutama dilingkungan keluarga diera milenial 
saat ini? Tentu hal ini peran orang tua sebagai pendidik pertama dilingkungan keluarga harus mengajarkan kepada anak yaitu pendidikan karakter sehingga anak memiliki moralitas dan karakter yang baik. Selain di lingkungan keluarga anak juga bisa mendapatkan pendidikan karakter melalui lingkungan sekolah dan masyarakat. Sebagai contoh pasraman, asrama dan lain sebagainya.

\section{SIMPULAN}

Pendidikan tidak dapat terlepas dari kehidupan manusia terutama pendidikan karakter. Pendidikan karakter hendaknya dilakukan terlebih dahulu dilingkungan keluarga karena lingkungan keluarga merupakan tempat anak belajar pertama dan utama. Perkembangan teknologi yang semakin canggih turut mempengaruhi karakter anak pada era milenial saat ini apapun bisa dicari secara cepat dan praktis tetapi dibalik itu juga ada dampak yang mungkin timbul dari perkembangan teknologi itu. Salah satu dampaknya yaitu merosotnya nilai moral dan karakter para remaja saat ini namun dari permasalahan itu diharapkan kita sebagai generasi penerus bangsa Indonesia bisa menumbuhkan moralitas dan karakter anak sejak usia dini teruma, peran orang tua didalam mengajarkan pendidikan karakter dilingkungan keluarga. Dengan menumbuhkan pendidikan karakter pada anak maka generasi muda yang akan datang bisa membawa Indonesia yang lebih baik.
Pendidikan karakter selain diajarkan melalui lingkungan keluarga bisa juga melaui lingkungan sekolah dan masyarakat.

\section{DAFTAR PUSTAKA}

Sukardjo Ukim Komarudin. 2013. Landasan Pendidikan, Jakarta:PT.Raja Grafindo Persada.

Abu Ahmadi \& Nur Uhbiyanti. 2001. Ilmu Pendidikan, Jakarta:PT.Rineka Cipta.

Hasbullah,2011. Dasar-dasar Ilmu Pendidikan, Jakarta:PT.Raja Grafindo Persada.

Iskandar,Metodologi Penelitian pendidikan dan Sosial, Jakarta:GP,2010.

Jurnal Kalangwan, Vol. 6, No. 1, Maret 2016.

Jurnal Kalangwan, Vol.8, No. 1, Maret 2018

Muslich,Masnur,2010. Pendidikan Karakter, Malang:Jakarta:Bumi Aksara.

Lickona,Thomas,2015.Educating for Character, Jakarta:Bumi Aksara.

Pf, K. A. P. D. (2017). Upacara

Otonan: Pemenuhan Kebutuhan Emosi Dasar Manusia Berbasis Kearifan Lokal Bali. Prosiding Sembada 2017.

Poerwadarminta, W.J.S.1987.Kamus Umum Bahasa Indonesia.Jakarta:Balai Pustaka. Undang-Undang Republik Indonesia Nomor 20 Tahun 2003,2010. UU Republik Indonesia No. 20 Tahun 2003. Bandung: Citra Umbara 